\title{
The clinical significance of anti-Müllerian hormone evaluation in gynecological endocrinology
}

\author{
Artemis Karkanaki, Christos Vosnakis, Dimitrios Panidis \\ Division of Endocrinology and Human Reproduction, $2^{\text {nd }}$ Department of Obstetrics and Gynecology, Aristotle University \\ of Thessaloniki, Ippokratio Hospital, Thessaloniki, Greece
}

\begin{abstract}
Anti-Müllerian hormone (AMH) is a homodimeric glycoprotein, a member of the transforming growth factor- $\beta$ superfamily. Over the last decade, a large number of studies examining the multiple roles of AMH have been published. AMH levels accurately reflect the ovarian follicular reserve and could, therefore, be considered as an extremely sensitive marker of ovarian aging and a valuable tool in the diagnosis and the recognition of recurrence of granulosa cell tumors. Furthermore, AMH evaluation is of clinical importance in predicting the success of in vitro fertilization (IVF). Additionally, AMH could be a surrogate diagnostic marker of polycystic ovary syndrome in cases in which ultrasonographic examination is not possible. This article is a review of the clinical usefulness of AMH evaluation in the fields of gynecological endocrinology, menopause, gynecological oncology and assisted reproduction. Special reference is made to the possible implications of AMH in the pathogenesis of polycystic ovary syndrome and the relationship between AMH and obesity.
\end{abstract}

Key words: Anti-Müllerian hormone, Assisted reproduction techniques, Obesity, Ovarian aging, PCOS, Tumor marker

\section{INTRODUCTION}

Anti-Müllerian hormone (AMH), also known as Müllerian inhibiting substance (MIS), is a homodimeric glycoprotein linked by disulfide bonds and a molecular weight of $140 \mathrm{kDa} .^{1}$ The hormone belongs to the Transforming Growth Factor- $\beta$ (TGF- $\beta$ ) superfamily. The gene encoding AMH is located in the short arm of chromosome $19 .{ }^{2} \mathrm{AMH}$ action is exerted

Address for correspondence:

Artemis Karkanaki, 30 Ioanninon Str, 54639 Thessaloniki, e-mail: kartemis2004@hotmail.com, Tel.: +306932315022

Received 05-09-10, Revised 12-12-10, Accepted 15-01-11 through two receptors: type I receptor (AMHRI) and type II receptor (AMHRII) which are present on the AMH target-organs (gonads and Müllerıan ducts). ${ }^{3}$

AMH plays an important role in male sex differentiation as its production by the embryonic testes induces the regression of Müllerian ducts. In the event of deficient production of AMH or dysfunction of its receptors, Müllerian ducts differentiate into oviducts, uterus and the upper third of the vagina in genetic male embryos. ${ }^{4}$

For the purpose of this study, a comprehensive search was conducted via MEDLINE (http://www. 
ncbi.nlm.nih.gov/entrez/medline.html) employing the keywords: anti-Müllerian hormone, AMH, MIS, PCOS, obesity, endocrinology, menopause, oncology, assisted reproduction. The search included all possible combinations of keywords without any limitation in language or date. Relevant citations in the reference lists of selected articles were also reviewed. Inclusion or exclusion of any article was based on relevance. Numerous studies related to clinical application of $\mathrm{AMH}$ in a variety of medical fields, as menopause, gynecologic endocrinology and oncology, have been published. The present article is a review of the literature on the implications of the hormone in the pathogenesis of polycystic ovary syndrome (PCOS) and its potential use as diagnostic or even prognostic marker of the syndrome. The recently reported association of obesity with AMH levels is also extensively discussed.

\section{AMH: PRODUCTION, LEVELS AND ACTIONS IN WOMEN}

In women, $\mathrm{AMH}$ is produced by the granulosa cells (GC) of follicles. Specifically, GC produce AMH from the stage of the primary follicle to the initial formation of the antrum. In female neonates, $\mathrm{AMH}$ is virtually undetectable but increases gradually until puberty and remains relatively stable thereafter and throughout the reproductive period. ${ }^{5}$

It is widely accepted that the reduction of AMH levels in serum is the first indication of a decline in the follicular reserve of the ovaries. AMH concentration remains stable throughout the menstrual cycle. ${ }^{6}$ Recent data, however, have shown that there are fluctuations throughout the cycle (with lower levels during the early secretory phase) or even between consecutive cycles. ${ }^{7}$ Nevertheless, these fluctuations are not considered clinically significant to recommend the measurement of AMH concentrations at a specific phase of the menstrual cycle. ${ }^{7}$

The data concerning the impact of oral contraceptives on AMH values are divergent. It has been suggested that AMH concentrations are not influenced by oral contraception, ${ }^{8}$ but this finding has not been confirmed. ${ }^{9}$ Contraceptives containing $35 \mathrm{mg}$ of ethynylestradiol and $2 \mathrm{mg}$ of cyproterone acetate cause a significant suppression of gonadotropins and testosterone levels, a reduction in the number of ovarian small follicles as well as a significant reduction in AMH levels. ${ }^{9}$ On the other hand, gonadotropinreleasing hormone (GnRH) agonists do not seem to affect AMH concentrations. ${ }^{10}$ Finally, there are no racial differences in the hormone levels between women of comparable age. ${ }^{11}$

The specific actions of AMH on the human ovaries have not yet been fully elucidated. It has been suggested that AMH inhibits the recruitment of primordial follicles and diminishes the response of the selectable follicles to FSH, thus impairing the selection of the dominant follicle. ${ }^{12}$ Most of the evidence regarding AMH actions has come from animal studies. Durlinger et al (1999) showed that AMH knock-out mice had three times more small non-atretic growing follicles and a reduced number of primordial follicles compared with wild mice. Although AMH null mice had low FSH levels, they still presented a large number of growing follicles. This fact led to the hypothesis that, in the absence of $\mathrm{AMH}$, follicles show a tendency to become more sensitive to FSH action. ${ }^{13,14}$ Furthermore, it has been reported that FSH and estradiol down-regulate $\mathrm{AMH}$ gene expression in GC of rat follicles. ${ }^{15}$ In a recent in vitro study, it was ascertained that the bone morphogenic protein-6 (BMP-6) augments AMH expression in GC of human follicles. ${ }^{16}$ The researchers assumed that the BMP- 6 produced by the GC of developing follicles increases $\mathrm{AMH}$ expression, which in turn inhibits the recruitment of primordial follicles, and hence ovarian function sustains its dynamic balance.

Ten years ago, a highly sensitive ELISA method for the evaluation of AMH levels in serum, plasma and follicular fluid was developed. ${ }^{17}$ To date, two ELISA kits are available, the Diagnostic System Laboratories (DSL) assay and the Immunotech Beckman (IB) assay. AMH levels seem to be four to five times lower when the DSL kit is used compared with the Immunotech Beckman kit. ${ }^{18}$ In a recent prospective study, AMH measurements provided comparable results by both the IB and DSL assays. ${ }^{7}$ There is a definite need for standardization in this field.

\section{AMH AS A MARKER OF OVARIAN AGING}

The number of primordial follicles decreases with 
age and is virtually depleted at menopause. AMH serum levels determined over a three-year period in young women with normal menstrual cycles has shown a significant fall in AMH, while FSH and inhibin B remained stable. Thus, AMH could be used as a marker of ovarian aging given that the reduction in hormone levels reflects the age-dependent fall in the follicular potential of the ovary. The decrease of AMH levels and follicle number with age has been widely accepted. ${ }^{19-21}$ Indeed, AMH values have greater sensitivity than inhibin $\mathrm{B}, \mathrm{FSH}$ and estradiol ${ }^{19}$ values in predicting ovarian follicular reserve.

It has been reported that $\mathrm{AMH}$ concentrations present a negative linear correlation with basal FSH levels in women who have a poor response to controlled ovarian stimulation with human gonadotropins. ${ }^{22}$ Specifically, AMH concentrations of $1 \mathrm{ng} / \mathrm{ml}$ correspond to $\mathrm{FSH}$ values of $10 \mathrm{IU} / \mathrm{L}$, whereas $0.5 \mathrm{ng} / \mathrm{ml}$ of $\mathrm{AMH}$ corresponds to $15 \mathrm{IU} / \mathrm{L}$. However, in conditions with high LH and normal or low FSH levels, as in PCOS, AMH concentrations are positively correlated with LH concentrations, while they are not negatively correlated with $\mathrm{FSH} .{ }^{23}$

The reduction of $\mathrm{AMH}$ concentrations has recently been reported as a reliable marker for the evaluation of the ovarian impairment caused by chemo- or radiotherapy. ${ }^{24,25}$ This knowledge could prove particularly helpful in fertility preservation in women subjected to such therapies.

\section{AMH IN ASSISTED REPRODUCTION}

The clinical significance of AMH determination was first proven in assisted reproduction medicine, as AMH serum levels reflect the ovarian reserve potential with high accuracy. AMH measurement is the best prognostic marker of the ovarian response to controlled ovarian stimulation during IVF cycles, especially when a single marker is determined. ${ }^{26,27}$ AMH levels have prognostic value for both the number of oocytes retrieved during follicular aspiration and the number of arrested cycles. ${ }^{27}$ Compared to antral follicle count, AMH concentrations could reliably and equally predict poor response to ovarian stimulation in IVF cycles. ${ }^{28}$ Recently, it was reported that AMH levels could recognise those women prone to express ovarian hyperstimulation syndrome (OHSS) during multiple ovulation induction with human gonadotropins. ${ }^{29}$ In a prospective study, it was found that the live birth rate, following IVF, was increased when $\mathrm{AMH}$ levels were high prior to ovulation induction with human gonadotropins. ${ }^{30}$ This could be attributed to the greater number of oocytes retrieved by women with high AMH levels, given that high basal AMH concentrations indicate a great number of selectable follicles. On the other hand, the results of a large meta-analysis showed that AMH levels are very poor predictors of pregnancy outcome. ${ }^{31}$ An alternative approach could be the evaluation of AMH levels in the follicular fluid. Fanchin et al. ${ }^{32}$ showed that AMH follicular fluid levels were strongly associated with pregnancy rates in IVF cycles, these findings also having been confirmed by other researchers. ${ }^{33}$ $\mathrm{AMH}$ levels measurement in oocyte donors were not decreased in women who underwent repetitive oocyte donation (three to six cycles), implying that ovarian aging is not advanced in oocyte donors as previously suspected. ${ }^{34}$

\section{AMH AS A TUMOR MARKER}

The fact that the expression of AMH is confined to GC of primary follicles up to the initial antral formation has rendered the evaluation of this hormone a candidate marker for the diagnosis of ovarian tumors of GC origin. Indeed, AMH levels are found increased in $76-93 \%$ of women with GC tumors. ${ }^{35-38}$ Moreover, elevation of AMH levels precedes the tumor clinical recurrence ${ }^{17}$ by up to 16 months. Consequently, AMH could be used as an early diagnostic marker as well as a marker of GC tumor recurrence (Table 1).

Table 1. Possible clinical applications of anti-Müllerian hormone levels evaluation in gynecology ${ }^{43}$

1. Evaluation of ovarian follicular reserve:

- in the general population

- in subfertile women prior to ovulation induction

- before and following chemo- and/or radiotherapy for cancer

2. Diagnosis and follow-up of polycystic ovary syndrome

3. Diagnosis and follow-up of ovarian tumors of granulosa cell origin

4. Prognosis of ovarian hyperstimulation syndrome risk during multiple ovulation induction 


\section{AMH AS A TUMOR INHIBITOR}

Although the origin of ovarian epithelial tumors has widely been thought to originate from the coelomic epithelium that covers the ovarian surface, a new and well supported theory has placed their origin in tissues that embryologically derive from Müllerian ducts. Recent data strongly indicate that a great number of tumors of ovarian origin arise from the fimbriated end of the fallopian tube as well as from components of the secondary Müllerian system. ${ }^{39}$ AMH induces the regression of Müllerian ducts. Based on this fact some researchers hypothesized that AMH could be used in the treatment of ovarian epithelial tumors. Indeed, several studies showed that AMH inhibited epithelial ovarian cancer cells in vitro. ${ }^{40,41}$ Nevertheless further studies are required to definitively establish whether AMH has potential for clinical use in the treatment of these tumors.

\section{AMH IN POLYCYSTIC OVARY SYNDROME}

Since AMH levels reflect the number of developing follicles, their measurement may be used as a marker of ovarian follicle impairment in polycystic ovary syndrome. PCOS is clinically diagnosed when at least two of the following three features are present: chronic oligo- or anovulation, biochemical hyperandrogenemia or hyperandrogenism and polycystic ovarian morphology in ultrasound examination (PCO).${ }^{42}$ The syndrome, which is diagnosed in 5-10\% of women of reproductive age, ${ }^{43-45}$ is the main cause of anovulatory infertility in developed countries. The common clinical manifestations of PCOS include menstruation disorders and androgen excess, hirsutism and male pattern alopecia. ${ }^{46}$

Polycystic ovary syndrome is also associated with metabolic aberrations. The incidence of diabetes mellitus type 2 is 10 -fold higher in women with PCOS compared to healthy women in the USA..$^{47,48}$ Furthermore, $30-50 \%$ of women with PCOS develop glucose intolerance or diabetes mellitus type 2 after the age of $30 .{ }^{47-49}$ The incidence of metabolic syndrome is two to three-fold higher among women with PCOS compared to healthy women of similar age and body mass index (BMI), while $20 \%$ of women with PCOS, aged less than 20 years have already manifested the metabolic syndrome. ${ }^{50}$ Although there is no prognosis regarding the outcome, especially for women with PCOS, the risk of fatal myocardial infarction is double among postmenopausal hyperandrogenemic women with a history of severe oligomenorrhoea, who are actually expected to be PCOS patients, compared to women with regular menstrual cycle. ${ }^{51}$

Women with PCOS have a two to six-fold greater number of follicles (primary, secondary and antral) in their ovaries, possibly due to the hyperandrogenemia. ${ }^{52}$ In anovulatory women with PCOS, the follicular development is halted when follicular diameter is $6-9 \mathrm{~mm}$, that is just before the selection of the dominant follicle. ${ }^{38}$

Earlier data showed that in women with PCOS, serum and follicular AMH levels are higher than in healthy controls ${ }^{53,54}$ (Table 2). Subsequent data confirmed this finding and indicated that the elevated levels of AMH were related to increased number of follicles with a diameter of $2-5 \mathrm{~mm}$ in women with PCOS. ${ }^{55}$ Hence, AMH serum values could be a precise, subsidiary diagnostic marker of the syndrome, particularly in cases in which the transvaginal ultrasound examination is not feasible ${ }^{56}$ (Table 1). The high AMH levels in women with PCOS are attributed to the high number of small antral follicles with a diameter of 2-5mm..$^{57}$ Additionally, these high AMH levels are probably related to the follicular arrest, during the selection process of the dominant follicle, through a negative interaction between $\mathrm{AMH}$ and FSH. If so, $\mathrm{AMH}$ inhibits the production of aromatase which is activated by FSH action on GC. ${ }^{58}$ On the other hand,

Table 2. Factors affecting anti-Müllerian (AMH) hormone serum levels $^{43}$

1. Factors that reduce AMH serum levels:
Aging
Increased body mass index
Ovariectomy
Chemo- and/or radiotherapy (permanent or temporary effect,
depending on the therapy)
Gonadotropin administration
Pregnancy
Oral contraceptives
2. Factors that increase AMH serum levels:
Polycystic ovary syndrome


in a large prospective study of adolescent population, although AMH serum levels were higher in adolescents with PCOS or PCO, the hormone was not proven to be a reliable predictor of PCO or PCOS..$^{59}$

In a recent in vitro study, it was found that $\mathrm{AMH}$ production per granulosa cell was increased by up to $75 \%$ in women with PCOS compared to controls. ${ }^{60}$ According to the authors, the higher levels should be attributed to the increased number of follicles as well as to the intrinsic aberrant follicular function. AMH excess, via endocrine or paracrine paths, would appear to play an essential role in the process of follicular arrest.

AMH concentrations in women with PCOS were independently and positively correlated with testosterone, androstendione and free androgen index (FAI) values. ${ }^{55,61}$ In a recent study, ${ }^{62} \mathrm{AMH}$ levels were determined in 200 women (100 normal weight and 100 overweight/obese) with PCOS and 50 controls $(\mathrm{C})$ matched for age and BMI. Women with PCOS were divided into four groups, according to their clinical, biochemical, and sonographic characteristics. Group1 included women with oligo- or amenorrhea (ANOV), hyperandrogenemia (HA), and polycystic ovarian morphology (PCO), group 2 included women with ANOV and HA, without PCO, group 3 included women with $\mathrm{HA}$ and $\mathrm{PCO}$, without ANOV, and group 4 included women with ANOV and PCO, without HA. In the studied groups, each comprised of 25 PCOS women, we found that AMH levels were significantly higher in women of groups 1 and 2 compared to those of groups 3 and 4 and controls. Additionally, AMH was higher in the women of groups 3 and 4 compared to controls. Finally, AMH values were independently and positively correlated with $\mathrm{LH}$ and testosterone levels and the number of small follicles (diameter of 2-9mm). In conclusion, the differences in $\mathrm{AMH}$ concentrations between the four phenotypic groups of PCOS reflected the severity of the syndrome. However, a subsequent study failed to prove any correlation of AMH with LH levels. ${ }^{55}$ This discrepancy could be attributed to the small number of women included in the latter study.

A great number of women with PCOS have insulin resistance and compensatory hyperinsulinemia. A correlation has been reported between AMH levels and HOMA-IR values in women with the syndrome, ${ }^{63}$ although this finding has not been confirmed by other studies. ${ }^{55,61,62}$ Treatment of obese PCOS women with metformin resulted in the reduction of androgens and AMH levels, without any significant decrease in follicle number. ${ }^{64,65}$ On the other hand, it was recently reported that six-month treatment with dexamethasone and metformin combined with lifestyle modifications did not alter AMH levels. ${ }^{66}$

It is known that $\mathrm{AMH}$ levels decrease with age in women with normal ovulatory cycles. A similar decline is observed in women with PCOS, but at a slower reduction rate. ${ }^{65}$ This could be interpreted as indicating that ovarian aging is slowed down in women with PCOS, possibly due to the negative effect of $\mathrm{AMH}$ on the recruitment of primordial follicles. High AMH levels were observed in adolescent girls, aged 12-18 years, with polycystic ovary syndrome compared to controls. ${ }^{67}$ Furthermore, increased AMH concentrations have been found in girls aged 4-7 years born of mothers with PCOS. ${ }^{68}$ Evidence that hereditary factors contribute to the pathogenesis of the syndrome is also found in animal studies showing that prenatal exposure to increased androgen levels can lead to offspring with PCOS features. ${ }^{69,70}$ Although these data support a genetic contribution to the pathogenensis of the syndrome, an environmental component cannot be excluded given the fact that prenatal exposure to high androgen levels as well as other unknown factors are operative.

Oxidative stress has recently been implicated in the pathogenesis of the anovulatory process. ${ }^{71}$ Women with anovulatory PCOS appeared to have increased oxidative stress $^{72}$ as well as products of oxidation and advanced glycation end products (AGEs) ${ }^{73}$ Increased serum AGEs is a distinct finding in lean women with polycystic ovary syndrome. A direct relationship between PCOS, anovulatory process and AGEs is supported by finding increased serum AGEs levels and increased expression of their receptors in macrophages (RAGE) ${ }^{74}$ as well as elevated deposition in ovarian tissues in PCOS women. ${ }^{75}$ More relevant is the finding of significant positive correlation between AMH levels and AGEs in normal weight women with PCOS. ${ }^{76}$ In this study, AMH and AGEs concentrations were evaluated in women with ovulatory PCOS, in women with anovulatory PCOS, in anovulatory 
women without the syndrome and in healthy controls. Their levels were significantly higher in the group of anovulatory PCOS as compared to the other study groups. The authors suggested a possible contribution of AMH and AGEs to the mechanism of anovulation in women with polycystic ovary syndrome. ${ }^{76}$

\section{AMH AND OBESITY}

There are very few studies evaluating the impact of obesity and weight loss on AMH levels, the existing studies concerning mostly overweight and obese women with PCOS. In a recent study, it was found that obese women of late reproductive age (35-49 years) had significantly lower AMH levels, (up to 65\%), compared to normal-weight women of similar age. ${ }^{77}$ This inverse correlation between BMI and AMH levels has not been fully explained. Three hypotheses have been proposed: a) obesity may affect the catabolism of AMH, b) obesity could reduce the ovarian potential, and c) obesity may be related to ovarian dysfunction. ${ }^{78}$ To date, none of the three hypotheses could be fully supported or rejected as the data are scarce. Certainly, more studies are necessary to elucidate the impact of obesity on ovarian function.

AMH levels were lower in overweight and obese women with PCOS than in normal-weight women with the syndrome and healthy controls. ${ }^{62}$ Other studies have also confirmed this finding. ${ }^{60,61}$ Furthermore, an independent positive correlation between AMH and LH levels has also been found. ${ }^{79}$ Previews research has also shown that normal-weight women with PCOS presented higher LH values than overweight and obese women with the syndrome, ${ }^{64}$ a finding which was confirmed by our study ${ }^{62}$ Thus, the lower LH concentrations observed in obese women may be attributed to the increased aromatization of androgens to estrogens which takes place in the peripheral fat tissue, resulting in the suppression of LH. ${ }^{80}$ Therefore, higher AMH levels seen in normal-weight women with PCOS compared to obese women with the syndrome could be attributed to the higher LH levels. This is further supported by an in vitro study showing that the addition of LH in cultures of granulosa cells from women with PCOS triples the amount of AMH produced. ${ }^{60}$

In the study of Mehri et al, ${ }^{81} \mathrm{AMH}$ levels were evaluated in obese women of variable age before and after the performance of bariatric surgery. Despite the small size of the sample, significant AMH reduction was found after the decrease of BMI in the group of young women but not in older age groups. The authors concluded that the small sample as well as the short follow-up period did not permit definitive conclusions.

Interestingly, in another study including a small number of obese women with PCOS who followed a program of weight loss and six-month maintenance, it was shown that the women with weight reduction and menstrual cycle improvement were those with significantly lower AMH levels before treatment. ${ }^{82}$ In contrast, the menstrual cycles of women who had higher AMH levels before losing weight did not improve. The authors recommended AMH measurement in overweight and obese women prior to weight loss program implementation as a prognostic tool of the menstrual cycle improvement. The same authors have recently published a study regarding the impact of weight loss on AMH concentrations. This study included overweight and obese women with PCOS subjected to a 20 -week course of hypocaloric diet. ${ }^{83}$ AMH levels were not significantly altered either in the group of women who lost weight or in those who did not respond to the diet. Again, women with lower $\mathrm{AMH}$ levels before treatment presented the greater improvement of menstrual irregularities.

\section{CONCLUSIONS}

AMH levels reflect with high accuracy the ovarian follicle reserve, and this has been demonstrated in numerous studies. Therefore, AMH evaluation has great clinical importance in predicting the success of IVF cycles. AMH levels represent the most sensitive marker for the inevitable decline in the number of primordial follicles related to aging. Furthermore, AMH determination can be used in the diagnosis or the follow-up of women with tumors of granulosa cell origin. Additionally, AMH could be used as a supplementary marker of polycystic ovary syndrome in cases where the ultrasonographic examination of the ovaries is not feasible. Finally, the recently revealed relation between AMH and obesity will be a future research target in pathogenetic mechanisms linking obesity and gonadal dysfunction. 


\section{REFERENCES}

1. Cate RL, Mattaliano RJ, Hession, et al, 1986 Isolation of the bovine and human genes for MIS and expression of the human gene in animal cells. Cell 45: 685-698.

2. Cohen-Haguenauer O, Picard Mattei JY, Mattei MG, et al, 1987 Mapping the gene for anti-Müllerian hormone to the short arm of human chromosome 19. Cytogenet Cell Genet 44: 2-6.

3. La Marca A, Volpe A, 2006 Anti-Müllerian hormone $(\mathrm{AMH})$ in female reproduction: is measurement of circulating AMH a useful tool? Clin Endocrinol 64: 603-610.

4. Behringer RR, Finegold MJ, Cate RL, 1994 Müllerian inhibiting substance function during mammalian sexual development. Cell 79: 415-425.

5. Lee MM, Donahoe PK, Hasegawa T, et al, 1996 Müllerian inhibiting substance in humans: normal levels from infancy to adulthood. J Clin Endocrinol 81: 571-576.

6. Cook CL, Siow Y, Taylor S, Fallat M, 2000 Serum Müllerian inhibiting substance levels during normal menstrual cycles. Fertil Steril 73: 859-861.

7. Streuli I, Fraisse T, Chapron C, Bijaoui G, Bischof P, deZiegler D, 2009 Clinical uses of anti-Müllerian hormone assays: pitfalls and promises. Fertil Steril 91: 226-230.

8. Streuli I, Fraisse T, Pillet C, Ibecheole V, Bischof P, de Ziegler D, 2008 Serum anti-Müllerian hormone levels remain stable throughout the menstrual cycle and after oral or vaginal administration of synthetic steroids. Fertil Steril 90: 395-400.

9. Panidis D, Georgopoulos N, Piouka A, et al, 2010 The impact of oral contraceptives and metformin on AntiMüllerian hormone serum levels in women with polycystic ovary syndrome. Gynecol Endocrinol 2010 (Epub ahead of print).

10. Mohamed KA, Davies WA, Lashen H, 2006 Anti-Müllerian hormone and pituitary gland activity after prolonged down regulation with gaserelin acetate. Fertil Steril 86: 1515-1517.

11. Seifer D, Golub E, Lambert-Messerilian G, et al, 2009 Variations in serum of Müllerian inhibiting substance between white, black and Hispanic women. Fertil Steril 92: 1674-1678.

12. Visser J, de Jong F, Laven J, Themen A, 2006 AntiMüllerian hormone: a new marker of ovarian function. Reproduction 131: 1-9.

13. Durlinger AL, Kramer P, Karels B, et al, 1999 Control of primordial follicle recruitment by anti-Müllerian hormone in the mouse ovary. Endocrinology 140: 5789-5796.

14. McGee EA, Hsuesh AJ 2000 Initial and cyclic recruitment of ovarian follicles. Endocr Rev 21: 200-214.

15. Baarends WM, Uilenbroek JT, Kramer P, Hoogebrugge JW, van Leeuwen EC, Themmen AP, 1995 Anti-Müllerian hormone and AMH type II receptor messenger ribonucleic acid expression in rat ovaries during postnatal development, the oestrous cycle and gonadotrophin induced follicle growth. Endocrinology 136: 4951-4962.

16. Shi J, Yoshimo Y, Oshuga Y, et al, 2009 Bone morhogenetic protien- 6 stimulates gene expression of follicle stimulating hormone receptor, inhibin/activin $\beta$ subunit and anti-Müllerian hormone in human granulose cells. Fertil Steril 92: 1794-8.

17. Long WQ, Ranchin V, Pautier P, et al, 2000 Detection of minimal levels of anti-Müllerian hormone during follow up patients with ovarian granulosa cell tumor by means of a highly sensitive immunosorbent assay. $\mathrm{J}$ Clin Endocrinol Metab 85: 540-544.

18. Bersinger NA, Winder D, Birkhauser MH, Guibourdenche J, 2007 Measurement of anti-Müllerian hormone by Beckman Coulter ELISA and DSL ELISA in assisted reproduction: differences between serum and follicular fluid. Clin Chim Acta 384: 174-175.

19. de Vet A, Laven JS, de Jong F, Themmen A, Fauser BC, 2002 Anti- Müllerian hormone serum levels: a putative marker for ovarian aging. Fertil Steril 77: 357-362.

20. Franchin R, Schonauer LM, Righini C, Guibourdenche J, Frydman R, Taieb J, 2003 Serum Anti-Müllerian hormone is more strongly related to ovarian follicular status than serum inhibin B, estradiol, FSH and LH on day 3. Hum Reprod 18: 323-327.

21. van Rooij IA, Tonkelaar I, Broekmans FJ, et al, 2004 Anti-Müllerian hormone is a promising predictor for the occurrence of the menopausal transition. Menopause 11: 601-606.

22. Singer T, Barad D, Weghofer A, Gleicher N, 2009 Correlation of anti-Müllerian hormone and baseline follicle stimulating hormone levels. Fertil Steril 91: 2616-2619.

23. Georgopoulos N, Saltamavros A, Decavalas G, Piouka A, Katsikis I, Panidis D, 2010 Serum AMH, FSH, and LH levels in PCOS. Fertil Steril 93: e13.

24. Lie Fong S, Lugtenburg PJ, Schipper I, et al, 2008 Anti-Müllerian hormone as a marker of ovarian function in women after chemotherapy and radiotherapy for haematological malignancies. Hum Reprod 23: 674-678.

25. Loverro G, Guarini A, Di Nero E, Giacomantonio L, Lavopa C, Liso V, 2007 Ovarian function after cancer treatment in young women affected by Hodgkin disease. Hematology 12: 141-147.

26. La Marca A, Sighinolfi G, Radi D, et al, 2010 AntiMüllerian hormone (AMH) as a predictive marker in assisted reproductive technology (ART). Hum Reprod Update 16: 113-130.

27. Al-Qahtami A, Groome N, 2006 Anti-Müllerian hormone: Cinderella finds new admirers. J Clin Endocrinol Metab 91: 3760-3762.

28. Broer S, Mol BW, Dolleman M, Fauser B, Broekmans JM, 2010 The role of anti-Müllerian hormone assessment in assisted reproductive technology outcome. Curr Opin Obstet Gynecol 22: 193-201.

29. Nakhuda GS, Chu MC, Wang J, Sauer M, Lobo RA, 2006 Elevated serum MIS levels may be a marker for ovarian hyperstimulation syndrome in normal women 
undergoing IVF. Fertil Steril 85: 1541-1543.

30. Nelson SM, Yates RW, Lyall H, et al, 2009 Anti-Müllerian hormone-based approach to controlled ovarian stimulation for assisted conception. Hum Reprod 24: 867-875.

31. Broekmans FJ, Kwee J, Hendriks DJ, 2006 A systematic review of tests predicting ovarian reserve and IVF outcome. Hum Reprod Update 12: 685-718.

32. Fanchin R, Mendez Lozano DH, Frydman N, 2007 Anti-Müllerian hormone concentrations in the follicular fluid of the preovulatory follicle are predictive of the implantation potential of the ensuing embryo obtained by in vitro fertilization. J Clin Endocrinol Metab 92: 1796-1802.

33. Wunder DM, Guibourdenche J, Birkhauser MH, Bersinger NA, 2008 Anti-Müllerian hormone and inhibin $\mathrm{B}$ as predictors of pregnancy after treatment by in vitro fertilization/intracytoplasmic sperm injecton. Fertil Steril 90: 2203-2210.

34. Orhan B, Li Q, Carr B, Leader B, Doody K, Doody K, 2010 Repetitive oocyte donaton does not decrease serum anti-Müllerian hormone levels. Fertil Steril 94: 905-912.

35. Rey R, Sabourin JC, Venara M, et al, 2000 Anti-Müllerian hormone is specific marker of sertoli -and granulose-cell origin in gonadal tumors. Hum Pathol 31: 1202-1203.

36. Gustafson ML, Lee MM, Scully RE, et al, 1992 Müllerian inhibiting substance as a marker for ovarian sex cord tumor. New Engl J Med 326: 1820-1826.

37. Rey RA, Lhomme C, Marcillac I, et al, 1996 AntiMüllerian as a serum marker of granulosa cell tumours of the ovary: comparative study with serum inhibin A and estradiol. Am J Obstet Gynecol 174: 958-965.

38. Rey R, Belville C, Nihoul-Fekete C, et al, 1999 Evaluation of gonadal function in 107 intersex patients by means of serum anti-Müllerian hormone measurement. J Clin Endocrinol Metab 84: 627-631.

39. Dubeau L, 2008 The cell of origin of ovarian epithelial tumours. Lancet Oncol 9: 1191-1197.

40. Masiakos PT, MacLaughlin DT, Maheswaran S, et al, 1999 Human ovarian cancer,cell lines and primary ascites all express the human Müllerian inhibiting substance (MIS) type II receptor, bind and are responsive to MIS. Clin Cancer Res 5: 3488-3499.

41. Stephen AE, Pearsoll LA, Christian BP, Donahoe PK, Vacanti JP, MacLaughlin DT, 2002 Highly purified Müllerian inhibiting substance inhibits human ovarian cancer in vivo. Clin Cancer Res 8: 2640-2646.

42. The Rotterdam ESHRE/ASRM-Sponsored PCOS Consensus Workshop Group, 2004 Revised 2003 consensus on diagnostic criteria and long term health risks related to polycystic ovary syndrome (PCOS). Hum Reprod 19: 41-47.

43. Knochenhauer ES, Key TJ, Kahsar-Miller M, Waggoner W, Boots LR, Azziz R, 1998 Prevalence of the polycystic ovary syndrome in unselected black and white women of the south-eastern United States: a prospective study. J Clin Endocrinol Metab 83: 3078-3082.
44. Diamanti-Kandarakis E, Kouli CR, Bergiele AT, et al, 1999 A survey of the polycystic ovary syndrome in the Greek island of Lesbos: hormonal and metabolic profile. J Clin Endocrinol Metab 84: 4006-4011.

45. Asuncion M, Calvo RM, San Millan JL, Sancho J, Avila S, Escobar-Morreale HF, 2000 A prospective study of the prevalence of the polycystic ovary syndrome in unselected Caucasian women from Spain. J Clin Endocrinol Metab 85: 2434-2438.

46. Nestler JE, 2008 Metformin for the treatment of the polycystic ovary syndrome. N Engl J Med 358: 47-54.

47. Ehrmann DA, Barnes RB, Rosenfield RL, Cvaghan MK, Imperial J, 1999 Prevalence of impaired glucose tolerance and diabetes in women with polycystic ovary syndrome. Diabetes Care 22: 141-146.

48. Legro RS, Kunselman AR, Dodson WC, Dunaif A, 1999 Prevalence and predictors of risk for type 2 diabetes mellitus and impaired glucose tolerance in polycystic ovary syndrome: a prospective, controlled study in 254 affected women. J Clin Endocrinol Metab 84: 165-169.

49. Legro RS, Gnatuk CL, Kunselman AR, Dunaif A, 2005 Changes in glucose tolerance over time in women with polycystic ovary syndrome: a controlled study. J Clin Endocrinol Metab 90: 3236-3242.

50. Apridonidze T, Essah PA, Luorno MJ, Nestler JE, 2005 Prevalence and characteristics of the metabolic syndrome in women with polycystic ovary syndrome. J Clin Endocrinol Metab 90: 1929-1935.

51. Solomon CG, Hu FB, Dunaif A, 2007 Menstrual cycle irregularity and risk for future cardiovascular disease. J Clin Endocrinol Metab 87: 2013-2017.

52. Norman RJ, Dewailly D, Legro RS, Hickley T, 2007 Polycystic ovary syndrome. Lancet 370: 685-697.

53. Fallat ME, Siow Y, Marra M, Cook C, Carrillo A, 1997 Müllerian inhibiting substance in follicular fluid and serum: a comparison of patients with tubal factor infertility, polycystic ovary syndrome and endometriosis. Fertil Steril 67: 962-965.

54. Cook C, Siow Y, Bremer AG, Fallat ME, 2002 Relation between Müllerian inhibiting substance and other reproductive hormones in untreated women with PCOS and normal women. Fertil Steril 77: 141-146.

55. Pigny P, Merlen E, Robert Y, et al, 2003 Elevated serum level of AMH in patients with polycystic ovary syndrome: relationship to the ovarian follicle excess and to the follicular arrest. J Clin Endocrinol Metab 88: 5957-5962.

56. Pigny P, Jonard S, Robert Y, Dewailly D, 2006 Serum AMH as a surrogate for antral follicle count for definition of polycystic ovary syndrome. J Clin Endocrinol Metab 91: 941-945.

57. Jonard S, Dewailly D, 2004 The follicular excess in polycystic ovaries, due to ovarian hyperandrogenism, may be the culprit for the follicular arrest. Hum Reprod Update 10: 107-117.

58. Grossman M, Nakajima S, Fallat M, Siow Y, 2008 Müllerian inhibiting substance inhibits cytochrome 
P450 aromatase activity in human granulosa lutein cell culture. Fertil Steril 89: 1364-1370.

59. Hart R, Doherty D, Norman R, et al, 2010 Serum antiMüllerian hormone (AMH) levels are elevated in adolescent girls with polycystic ovaries and the polycystic ovarian syndrome (PCOS). Feril Steril 94: 1118-1121

60. Pellat L, Hanna L, Brinmat M, Galea R, Brain H, Whitehead S, 2007 Granulosa cell production of anti-Müllerian hormone is increased in polycystic ovaries. J Clin Endocrinol Metab 92: 240-245.

61. Laven JS, Mulders AG, Visser JA, Themmen APN, De Jong FH, Fauser BC, 2004 Anti-Müllerian hormone serum concentrations in normoovulatory and anovulatory women of reproductive age. J Clin Endocrinol Metab 89: 318-323.

62. Piouka A, Farmakiotis D, Macut D, Gerou S, Katsikis I, Panidis D, 2009 Anti-Müllerian hormone levels are increased in women with classical PCOS and are negatively influenced by obesity. Am J Physiol Endocrinol Metab 296: E238-243.

63. La Marca A, Orvieto R, Guilini S, Jasonni VM, Volpe A, DeLeo V, 2004 Müllerian inhibiting substance in women with polycystic ovary syndrome: relationship with hormonal and metabolic characteristics. Fertil Steril 82: 970-972.

64. Fleming R, Harborne L, MacLaughlin DT, et al, 2005 Metformin reduces serum Müllerian substance levels in women with PCOS after protracted treatment. Fertil Steril 20: 130-136.

65. Piltonen T, Morin-Papunen L, Koivunen R, Perheentupa A, Ruokonen A, Tapanainen JS, 2005 Serum AMH levels remain high until late reproductive age and decrease during metformin treatment in women with polycystic ovary syndrome. Hum Reprod 20: 1820-1826.

66. Carlsen SM, Vanky E, Fleming R, 2009 Anti-Müllerian hormone concentrations in androgen suppressed women with polycystic ovary syndrome. Hum Reprod 24: 17321738.

67. Siow Y, Kives S, Hertweek P, Perlman S, Fallat ME, 2005 Serum Müllerian inhibiting substance levels in adolescent girls with normal menstrual cycles or with polycystic ovary syndrome. Fertil Steril 84: 938-944.

68. Sir Petermann T, Conder T, Mliqueo M, Echiburu B, Hitschfeld C, Cristoto N, 2006 Increased anti-Müllerian hormone serum concentrations in prepubertal daughters of women with polycystic ovary syndrome. J Clin Endocrinol Metab 91: 3105-3109.

69. Zhou R, Bird IM, Dumesic DA, Abbott DH, 2005 Adrenal hyperandrogenism is induced by fetal androgen excess in a rhesus monkey model of polycystic ovary syndrome. J Clin Endocrinol Metab 90: 6630-6637.

70. Rosenfield RL, 2007 Identifying children at risk for polycystic ovary syndrome. J Clin Endocrinol Metab 92: 787-796.

71. Tatone C, Amicarelli F, Carbone MC, et al, 2008 Cellular and molecular aspects of ovarian follicle ageing. Hum Reprod Update 14: 131-142.

72. Victor VM, Rocha M, Bañuls C, et al, 2009 Mitochondrial Complex I Impairment in Leukocytes from Polycystic Ovary Syndrome Patients with Insulin Resistance. J Clin Endocrinol Metab 94: 3505-3512.

73. Diamanti-Kandarakis E, Katsikis I, Piperi C, et al, 2008 Increased serum advanced glycation end-products is a distinct finding in lean women with polycystic ovary syndrome. Clin Endocrinol (Oxf) 69: 634-641.

74. Diamanti-Kandarakis E, Piperi C, Kalofoutis A, Creatsas G, 2005 Increased levels of serum advanced glycation end-products in women with polycystic ovary syndrome. Clin Endocrinol 62: 37-43.

75. Diamanti-Kandarakis E, Piperi C, Patsouris E, et al, 2007 Immunohistochemical localization of advanced glycation end products (AGEs) and their receptor (RAGE) in polycystic and normal ovaries. Histochem Cell Biol 127: 581-589.

76. Diamanti-Kandarakis E, Piouka A, Livadas S, et al, 2009 Anti-Müllerian hormone is associated with advanced glycosylated end products in lean women with polycystic ovary syndrome. Eur J Endocrinol 160: 847-853.

77. Freeman E, Gracia C, Sammel MD, Lin H, Lim LC, Strauss JF 3rd, 2007 Association of anti-Müllerian hormone levels with obesity in late reproductive age women. Fertil Steril 87: 101-106.

78. Seifer D, MacLaughlin D, 2007 Müllerian inhibiting substance is an ovarian growth factor of emerging significance. Fertil Steril 88: 539-546.

79. Panidis D, Farmakiotis D, Rousso D, Katsikis I, Kourtis A, Diamanti-Kandarakis E, 2005 Serum LH levels are markedly increased and significantly correlated with Delta 4-androstendione levels in lean women with polycystic ovary syndrome. Fertil Steril 84: 538-540.

80. Katsikis I, Karkanaki A, Misichronis G, Delkos D, Kandaraki EA, Panidis D, 2011 Phenotypic expression, body mass index and insulin resistance in relation to $\mathrm{LH}$ levels in women with polycystic ovary syndrome. Eur J Obstet Gynecol Reprod Biol [Epub ahead of print]

81. Mehri Z, Minkoff H, Feldman J, Macura J, Rodriguez C, Seifer D, 2008 Relationship of bariatric surgery to Müllerian inhibiting substance levels. Fertil Steril 90: 221-224.

82. Moran L, Noakes M, Clifton M, Norman R, 2007 The use of anti-Müllerian hormone in predicting menstrual response after weight loss in overweight women with polycystic ovary syndrome. J Clin Endocrinol Metab 92: 3796-3802.

83. Thomson RL, Buckley JD, Moran LJ, Noakes M, Clifton RJ, Brinkworth GP, 2009 The effect of weight loss on AMH levels in overweight and obese women with polycystic ovary syndrome and reproductive impairment. Hum Reprod 24: 1976-1981. 